\title{
FUNCTIONAL STENOSIS AS A CAUSE OF PELVI-URETERIC OBSTRUCTION AND HYDRONEPHROSIS*
}

\author{
BY \\ L. BÄCKLUND, G. GROTTE, and A. REUTERSKIÖLD \\ From the Department of Clinical Physiology and the Department of Paediatric Surgery, \\ University of Uppsala, Uppsala, Sweden
}

The operative findings in cases of hydronephrosis often do not suggest any obvious cause of obstruction, and as Innes Williams (1958) has recently emphasized the pathology of hydronephrosis cannot be discussed solely in terms of anatomy. When by pyelography the diagnosis of hydronephrosis in a child has been established, the cause of the hydronephrosis can be one out of many. From the surgical point of view the common problem at operation is to find out if an aberrant vessel might cause the obstruction, or if there is an obstruction at the pelvi-ureteric junction, usually then a 'congenital stenosis'. In many cases, no cause of obstruction is found in the tissues surrounding the pelvis and the pelvi-ureteric junction. When the pelvi-ureteric junction is opened it looks narrow, though it is possible to pass a fine ureteric catheter; by definition the urologist would not call this a stenosis, and hydrodynamic flow would be considered free in such cases. In the present investigation four cases of pelvi-ureteric obstruction have been studied during continuous infusion into the pelves at various rates of flow. During this infusion pressures have been continuously recorded in the pelvis and at two different levels of the ureter. A fifth case having calyceal dilatation but normal pelvi-ureteric junction was also studied. The data from this small series suggest the existence of a 'functional stenosis', in spite of the passage of ureteral catheters.

\section{Material and Methods}

At operation the kidney and the proximal ureter were exposed through a flank incision. Two catheters, infant feeding tubes size $5 \dagger$, were inserted into the part of the dilated pelvis that was to be resected (Fig. 1). One of these was then used for infusion of Salidex (Pharmacia

\footnotetext{
* A paper read at a meeting of the British Association of Paediatric Surgeons in Rotterdam, September 1964.

$\dagger$ Bardic Inc. N.J., U.S.A
}

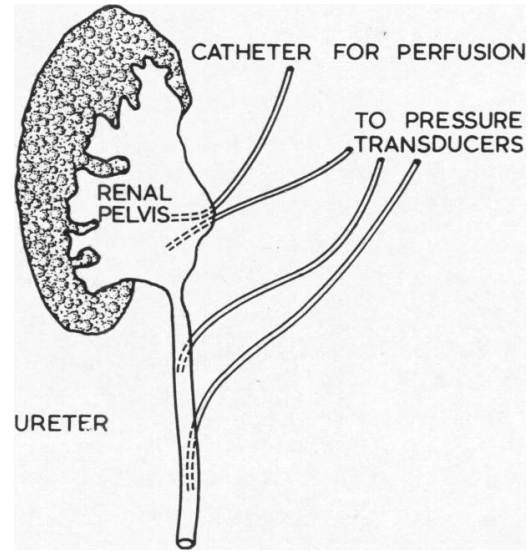

FIG. 1.-Arrangement of catheters during experiment.

Ltd., Uppsala, Sweden) at arbitrary flows. The rates of flow used varied between $0 \cdot 10-10 \cdot 0 \mathrm{ml}$./min. The other pelvic catheter was attached to the pressure recording apparatus. For this study a pressure recording device consisting of three pressure transducers (EMT 490 a) and electromanometers (EMT 469) and a direct writing recorder (Mingograf 42) was used. According to the manufacturer* the transducers work linearly from 0 to + $300 \mathrm{~mm}$. Hg. They had a volume displacement of 0.07 c.mm. when exposed to $100 \mathrm{~mm}$. $\mathrm{Hg}$. The two pelvic catheters were tied in by water-tight ligatures. Two other catheters $\dagger$ were then introduced into the ureter by puncture, one into the upper and the other into the lower ureter (Fig. 1). These two ureteric catheters were also connected to the pressure recording device. Leakage from any of the catheters was controlled after each experiment. Continuous infusion was obtained by a machine built by Mr. B. Clementz at the Institute of Physiology, University of Lund.

\footnotetext{
* Elema-Schönander Ltd. Stockholm, Sweden.

† Intracath, Desereth, needle size 17 Bardic Inc., N.J., U.S.A.
} 
TABLE 1

PRINCIPAL DATA CONCERNING PATIENTS

\begin{tabular}{|c|c|c|c|c|c|c|}
\hline Case No. & Diagnosis & $\begin{array}{c}\text { Age at Onset } \\
\text { of Symptoms } \\
\text { (yr.) }\end{array}$ & $\begin{array}{c}\text { Age at } \\
\text { Operation } \\
\text { (yr.) }\end{array}$ & $\begin{array}{l}\text { Maximum Infusion } \\
\text { Rate Without } \\
\text { Pronounced Rise } \\
\text { in Intrapelvic } \\
\text { Pressure (ml./min.) }\end{array}$ & $\begin{array}{c}\text { Infusion } \\
\text { Time } \\
\text { (min.) }\end{array}$ & $\begin{array}{l}\text { Correspond- } \\
\text { ing Diuresis } \\
\text { (ml./hr./ } \\
\text { kidney) }\end{array}$ \\
\hline $1 \mathrm{M}$ & $\begin{array}{l}\text { Hydronephrosis due to pelvi- } \\
\text { ureteric obstruction }\end{array}$ & $2 / 12$ & $4 / 12$ & $\leqq 0 \cdot 56$ & 10 & 34 \\
\hline $\begin{array}{ll}2 & \mathbf{F} \\
3 & \mathbf{M}\end{array}$ & ", & $\begin{array}{l}6 / 12 \\
9 \\
2 / 12\end{array}$ & $\begin{array}{l}4 \\
9 \\
3 / 12\end{array}$ & $\begin{array}{l}1 \cdot 10 \\
3 \cdot 2\end{array}$ & $\begin{array}{l}9 \cdot 5 \\
6\end{array}$ & 192 \\
\hline $\begin{array}{ll}4 & F \\
5 & M\end{array}$ & $\begin{array}{l}\text { Pyelonephritis" with normal } \\
\text { pelvi-ureteric junction }\end{array}$ & 14 & 20 & $\begin{array}{r}3 \cdot 2 \\
>5 \cdot 6\end{array}$ & $\frac{2 \cdot 5}{5}$ & $\begin{array}{r}192 \\
>312\end{array}$ \\
\hline
\end{tabular}

\section{Present Series}

Five patients have been studied. Their ages at the onset of symptoms and at the operation are shown in Table 1.

The symptoms in Cases 1-3 were recurrent urinary infections. Case 4 had had diffuse pains in her right side from 14 years of age, but no diagnosis was made until she had a right-sided pyelonephritis at the age of 20 . Pyelography in these four cases showed hydronephrosis with stenosis of the pelvi-ureteric junction. Operation revealed a so-called stenosis in all cases, but it was possible in every instance to pass a catheter Charr 2-3 from the renal pelvis through the stenosis into the ureter. After the flow-pressure studies were completed a HyneAnderson type of plastic operation was done (Anderson, 1963). The post-operative course was uneventful in every case.

Case 5 may be regarded as a control case. He had multiple malformations, high rectal atresia, agenesis of four sacral vertebrae, and bilateral congenital dislocation of the hips. At the age of 3 months he acquired his first urinary infection. Repeated intravenous pyelography showed dilatation of the calyces, but no significant dilatation of the renal pelvis of the right kidney. Because of recurrent infections, an exploration of the right kidney was made, but no hydronephrosis or pelvi-ureteric stenosis was confirmed. The calyceal dilatation was apparently due to severe pyelonephritic scarring.

\section{Results}

The intrapelvic pressure was measured before the perfusion started and was found to vary between 0 and $10 \mathrm{~mm} . \mathrm{Hg}$ (Table 2).

TABLE 2

RESTING PELVIC PRESSURE BEFORE AND MAXIMUM PELVIC PRESSURE DURING INFUSION

\begin{tabular}{c|c|c|c}
\hline Case No. & $\begin{array}{c}\text { Initial } \\
\text { Intrapelvic } \\
\text { Pressure } \\
\text { (mm. Hg) }\end{array}$ & $\begin{array}{c}\text { Maximum } \\
\text { Recorded } \\
\text { Pelvic } \\
\text { Pressure } \\
\text { (mm. Hg) }\end{array}$ & $\begin{array}{c}\text { Perfusion Rate at } \\
\text { Maximum Recorded } \\
\text { Pelvic Pressure } \\
\text { (mm. Hg) }\end{array}$ \\
\hline 1 & 0 & 25 & $0.56 \mathrm{ml} . / \mathrm{min}$. \\
2 & 10 & 38 & 0.56 \\
3 & 0 & 20 & 10.0 \\
4 & 2 & 20 & 10.0 \\
5 & $1-2$ & 2.5 & 5.6 \\
\hline
\end{tabular}

The infusion was then started and the pressures in the pelvis and ureter were continuously recorded. We tried to find the maximum perfusion rate not inducing a marked increase in pelvic pressure. The infusion time at that pressure is, together with other data, shown in Table 1. Higher rates of perfusion always gave a rapid increase in pelvic pressure. As can be seen the patients who started showing symptoms during the first year of life (Cases 1-2) did not tolerate as high a perfusion rate as those with a later onset of symptoms (Cases 3 and 4). As a contrast Case 5 is shown who, in spite of being very young, tolerated more than the 20-year-old girl (Case 4). The relation between the maximum recorded pelvic pressure and the corresponding infusion rate in the five cases is shown in Table 2. The recordings from a typical case (No. 2) are illustrated in Fig. 2a-c. The frequency of ureteric contractions was also studied. There was no change in contraction frequency with increasing perfusion rates in Cases 1, 3, and 4, whereas Case 2 showed a slight increase. In Case 5, however, the frequency of ureteric contractions was doubled during an increase of rates of perfusion used from minimum to maximum.

\section{Discussion}

It is well known from the works of Underwood (1937), Davis (1954) Melick, Karellos, and Naryka (1961), and Kiil (1963) that the resting pressure in the hydronephrotic sac is not very high. This is confirmed here. In our series, however, the patient was dehydrated and anaesthetized and probably had a very small flow of urine, so it would have been possible for the hydronephrotic sac to empty itself and lower the pelvic pressure during the start of the operation before the catheters were put in place. This is in agreement with the fact that after stopping the infusion, intrapelvic pressure decreased in our series within a few minutes. Why pressure in the hydronephrotic sac is so low has been discussed by many authors (Hinman, 1963). No doubt the 


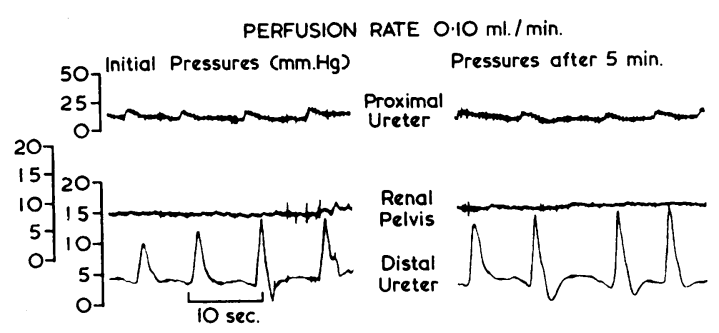

FIG. 2a.

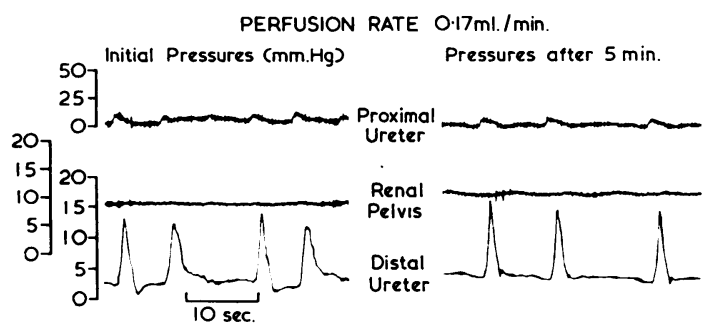

FIG. 2b.



Pressure recordings in renal pelvis, upper and lower ureter in Case 2 , at three different flow-rates. Note increasing pelvic pressure at flow-rates over $0 \cdot 10 \mathrm{ml} . / \mathrm{min}$.

pyelo-lymphatic, the pyelo-venous, and the pyelotubular backflow is involved in this mechanism.

For pelvic pressure recordings and infusion, most earlier investigators have used a catheter through the pelvi-ureteric junction inserted from below. These catheters no doubt disturb the outflow through the pelvi-ureteric junction. This is circumvented in our studies. With different perfusion rates we tried to mimic a diuresis within physiological limits. Within these flows we found a threshold value of interest, i.e. the maximum flow not inducing an increase in intrapelvic pressure during prolonged perfusion. According to Kiil (1957) the normal renal pelvis and ureter can tolerate a flow of $8-10 \mathrm{ml}$./ min. per ureter without increasing pelvic pressure. The threshold values in Cases 1 to 4 are therefore considered to be quite low. On the other hand Case 5 showed a transport capacity of more than $5.6 \mathrm{ml} . / \mathrm{min}$., i.e. within the range for adults. No similar studies on children seem to have been reported.

Those patients having functional stenosis of the pelvi-ureteric junction are prone to get episodes of pelvic hypertension during moderate diuresis. This pelvic hypertension may promote pyelonephritis (Beeson, 1963).

May a pelvi-ureteric obstruction be explained by any structural deviation from the normal? Murnaghan $(1958 \mathrm{a}, \mathrm{b})$ found a lack of circular muscles in the pelvi-ureteric junction in cases of pelvi-ureteric stenosis. However, no obvious anatomical stricture can be found at operation, and the abnormal histology must in some way interfere with the function. An explanation could be that when the urine enters the ureteral cone insufficient stretch reflex is elicited in the circular muscle and there is inadequate stimulus for the ureter to propel the urine. The importance of mechanical stimulation to the ureter was pointed out by Bäcklund (1963) among others; he studied the conduction mechanism of the ureter in dogs. A certain minimum distension of the smooth muscle is necessary to promote propagation. The orientation of the muscle fibres may be of importance in this connexion. It seems logical to assume that circular fibres become more distended and are therefore more easily excited than longitudinal muscles at increasing pressure in the ureteral cone. If the intraluminal pressure is not high enough to produce an adequate muscular distension in the abnormal region (lacking circular layer), the urine may merely be pressed through the abnormal segment without causing any peristalsis until it reaches a lower segment of the ureter. In Cases 1 to 4 it was found that in spite of increasing perfusion rates the ureteric activity remained fairly constant. In contrast to this the ureteric activity was doubled during increased perfusion in Case 5 who had a normal pelvi-ureteric junction. This may indicate that the flow through the ureteral cone is of the same magnitude in cases of functional pelvi-ureteric stenosis but varies with diuresis in the normal.

\section{Summary}

Four cases of hydronephrosis with evidence of pelvi-ureteric obstruction have been studied. A functional rather than an anatomical stenosis of the pelvi-ureteral junction is suggested.

This investigation was supported by generous grants from 'Ollie och Elof Ericssons Stiftelse för Vetenskaplig Forskning', Atvidaberg, Sweden. 


\section{REFERENCES}

Anderson, J. C. (1963). Hydronephrosis. Heinemann, London.

Bäcklund, L. (1963). Experimental studies on pressure and contractility in the ureter. Acta. physiol. scand., 59, suppl. 212.

Beeson, P. B. (1963). Pyelonephritis and renal infections. In Yearbook of Urology 1962-1963, ed. W. W. Scott, p. 121. Year Book Medical Publishers, Chicago.

Davis, D. M. (1954). The hydrodynamics of the upper urinary tract (urodynamics). Ann. Surg., 140, 839.

Hinman, F., Jr. (1963). The pathophysiology of urinary obstruction. In Urology, ed. M. F. Campbell, vol. 1, p. 323. Saunders, Philadelphia and London.

Kiil, F. (1957). The Function of the Ureter and Renal Pelvis. Saunders, Philadelphia and London.
- (1963). Physiology of the renal pelvis and ureter. In Urology, ed. M. F. Campbell, vol. 1, p. 81. Saunders, Philadelphia and London.

Melick, W. F., Karellos, D., and Naryka, J. J. (1961). Pressure studies of hydronephrosis in children by means of the strain gauge. J. Urol. (Baltimore), 85, 703.

Murnaghan, G. F. (1958a). The dynamics of the renal pelvis and ureter with reference to congenital hydronephrosis. Brit.J. Urol., $30,321$.

- (1958b). The mechanism of congenital hydronephrosis with reference to the factors influencing surgical treatment. Ann. roy. Coll. Surg. Engl., 23, 25.

Underwood, W. E. (1937). Recent observations on the pathology of hydronephrosis. Proc. roy. Soc. Med., 30, 817.

Williams, D. Innes (1958). Urology in Childhood (Handbuch der Urologie, ed. C. E. Alken et al., XV), p.26. Springer, Berlin. 